\title{
Framework for Solid-Organ Transplantation During COVID-19 Pandemic in Europe
}

\author{
Daniela Kniepeiss ${ }^{1,2}$ \\ Lydia Jantscher ${ }^{3,4}$ \\ Shahdy Al-Sharafy ${ }^{1,2}$ \\ Gerald Sendlhofer ${ }^{3,4}$ \\ Peter Schemmer ${ }^{1,2}$ \\ 'General, Visceral, and Transplant \\ Surgery, Department of Surgery, Medical \\ University of Graz, Graz, Austria; \\ ${ }^{2}$ University Transplant Center Graz \\ (UTCG), Medical University Graz,, Graz, \\ Austria; ${ }^{3}$ Research Unit for Safety in \\ Health, c/o Division of Plastic, Aesthetic, \\ and Reconstructive Surgery, Department \\ of Surgery, Medical University of Graz, \\ Graz, Austria; ${ }^{4}$ Executive Department for \\ Quality and Risk Management, University \\ Hospital Graz, Graz, Austria
}

Correspondence: Peter Schemmer

General, Visceral and Transplant Surgery, Department of Surgery, Medical

University of Graz, 29 Auenbruggerplatz,

Graz 8036, Austria

Email peter.schemmer@medunigraz.at
Introduction: Since the effect of the COVID-19 pandemic on solid-organ transplantation (SOT) is unclear, an online survey on the specific framework of leading European transplant centers ( $\mathrm{n}=155)$ in 31 European countries was conducted between April 24 and May 15, 2020. Methods: A questionnaire was designed to collect information on restrictions on SOT, protective measures,(non)governmental information policies, and individual opinions on how to deal with SOT during COVID-19.

Results: The response rate was $37.4 \%$ (58 of 155). Overall, $84.5 \%$ reported an effect of COVID-19 on SOT in Europe. In 49\% of these, limited capacity was mentioned, and in 51\% the reason for restricted resources was strategic preparedness. As a result, SOT was totally or partially suspended for several weeks. In sum, 93.1\% of centers implemented protective measures against COVID-19. Nongovernmental information policies were felt to be adequate in $90 \%$. Continuation of transplant activities was desired by $97 \%$ of centers.

Conclusion: The results of this survey suggested a need for more ICU capacity during COVID-19, in order to guarantee adequate and timely treatment of other patient cohorts in surveyed countries.

Keywords: transplantation, COVID-19 pandemic, restrictions, strategic preparedness

\section{Introduction}

Coronavirus type 2 is responsible for severe acute respiratory syndrome (SARS-CoV 2), as well as the associated COVID-19, which occurred first in Wuhan, China in December 2019. ${ }^{1,2}$ The virus spread around the world within a few weeks ${ }^{2}$ and became a public-health emergency of international concern at the end of January ${ }^{3}$ and a pandemic on March 11, 2020. ${ }^{4}$ At that point, the number of new cases in Europe had gone beyond those in China, and cases were doubling (depending on the country) within a few days. ${ }^{5}$ All countries within Europe had confirmed cases of COVID-19 patients and deaths. The most affected countries were Italy, Spain, France, and the UK. In order to prevent further spread of the virus, most European governments established lockdowns, including self-isolation, social distancing, closing schools, and banning of events, which affected $>250$ million people. ${ }^{6}$ During 2020 , lockdowns and further waves of the pandemic alternated and were a never-ending challenge for hospital management and politics. At the time of writing, more than 102 million confirmed COVID-19 cases and over 2 million deaths have been reported worldwide. ${ }^{7}$

Due to the COVID-19 pandemic, new challenges for health-care systems in all countries have arisen and there has been uncompromising prioritization of capacity of hospital facilities and human resources toward COVID-19 patients. Depending 
on the severity of the wave of infections, there was also a shortage of resources by actual capacity (eg, Italy, Spain) $)^{4,5,7}$ or by governmental and/or hospital policies in the sense of strategic preparedness (eg, Germany, Austria, Baltic states). In both cases, treatment was restricted for all other patient cohorts but emergencies. Surgical societies drew up lists of procedures that could be performed during the pandemic, including transplantations as life-saving procedures. $^{8}$ The impact of COVID-19 on solid-organ transplantation (SOT) was limited at the beginning of the pandemic $^{9-11}$ and is still unclear and controversial. ${ }^{12-18}$ Furthermore, it is unknown whether it affects the donor pool or whether there is a risk of virus transmission during transplantation. In addition, the risk of infection of living donors and of possibly poorer outcomes for organ recipients is still not clear. Since there are no evidence-based guidelines to deal with COVID-19 and transplantation, many centers have considered restricting (urgency, risk stratification) or even stopping their activities. ${ }^{11,19,20}$

To evaluate the framework for SOT in Europe during the first lockdown, we conducted an online survey between April 24 and May 15, 2020. A questionnaire to collect information on restrictions on SOT, protective measures, (non)governmental information policies, and individual opinion on how to deal with SOT during COVID-19 was designed.

\section{Methods}

\section{Study Population and Survey Conduct}

The survey link was distributed between April 24 and May 15, 2020 by email to transplant surgeons at established centers $(n=155)$ within 31 European countries. It was requested that the survey be filled out only once per center. Three reminders were automatically sent at weekly intervals to those who did not respond to the initial email. Only fully completed surveys were able to be returned.

\section{Survey Design and Topics}

This questionnaire on COVID-19 and SOT was created at the General, Visceral, and Transplant Surgery division, Medical University of Graz, Austria (Figure 1). The survey comprised multiple-choice questions and yes/no questions. Depending on the answer in the latter, more detailed questions were asked.

The first part of the survey included general questions on location (country) of the transplant center, hospital size, represented by total beds (up to 500, up to 1,000, up to
1,500 , up to $2,000,>2000$ ), and both total intensive care unit (ICU) beds and intermediate-care unit (IMC) beds (up to 20 , up to 50 , up to 100 , up to $150,>150$ ).

Furthermore, specific data of transplant centers were evaluated including transplant dedicated capacity, ie, ICU/ IMC beds, (up to five, up to ten, up to 20, >20). Moreover, both number of transplantations per year (up to 25, up to 50 , up to $100,>100$ ) and number of transplant surgeons (up to five, up to ten, up to $20,>20$ ) were asked about. There was a requirement to fill in the type of organ and the origin of grafts (deceased, living).

\section{Survey Topics}

Data on the following topics were collected:

(I) Restrictions on SOT (questions 3.1-3.8): It was asked whether there had been an effect on the transplant program, and if yes, whether it was caused by shortage of resources or by hospital or governmental policies. In both cases, we intended to find out which resources were limited (beds, equipment, medication, staff) and whether there was a related impairment of the transplant program (same selection, but additionally "only for highly urgent or the sickest patients" in liver, kidney, heart, and lung transplantation). Finally, it was asked if the respondent personally agreed with hospital or governmental policies.

(II) Protective measures (questions 3.10-3.16): These questions summarized protective measures against COVID-19. It was asked whether there were protective measures in the transplant program. If yes, further details were requested, including isolation of the recipient (if yes, single room, single room + airlock, or single room + airlock + overpressure system), visit ban, maximum number $(n=2)$ of health-care professionals at once with the patient, recipient wearing mask if with health-care professionals (if yes, surgical mask, filtering face piece [FFP] 2 mask, or FFP3 mask), health-care professionals wearing masks if with recipient (if yes, surgical mask, FFP2 mask, or FFP3 mask), and rapid hospital discharge. Furthermore, we asked about COVID-19 PCR testing of the donor and the recipient, and finally we investigated changes in immunosuppressive regimens or prophylactic medication with antibiotics, antimycotics, or antiviral therapy. 


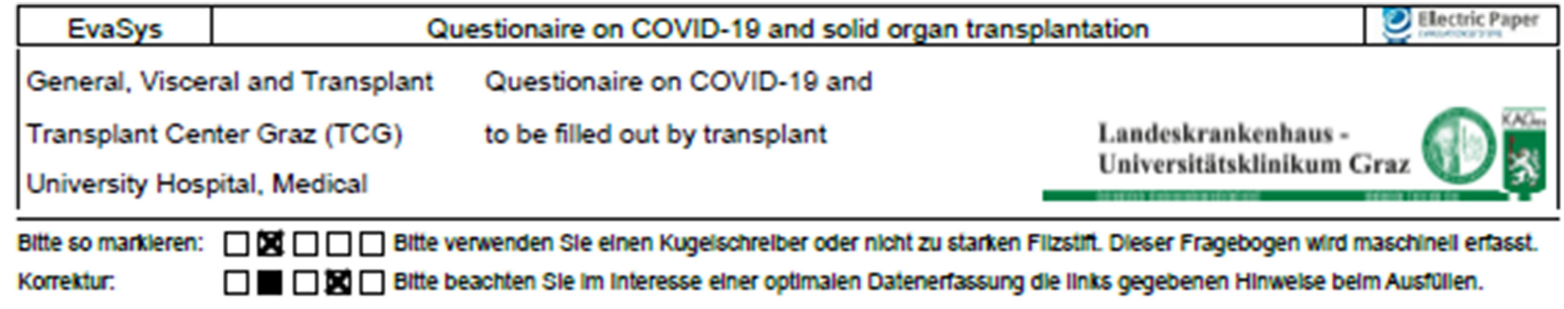

\section{General questions}

1.1 Country

Hospital size

1.2 Total number of beds

$\begin{array}{lll}\square \text { up to } 500 & \square \text { up to } 1000 & \square \text { up to } 1500 \\ \square \text { up to } 2000 & \square>2000 & \square \text { up to } 100 \\ \square \text { up to } 20 & \square \text { up to } 50 & \square>150 \\ \square \text { up to } 150 & \square \text { up to } 50 & \square \text { up to } 100 \\ \square \text { up to } 20 & \square>150 & \\ \square \text { up to } 150 & \square \text { up }\end{array}$

14 Total number of IMC beds

1.4 Total number of IMC-beds

$\square>150$

\section{Transplant program}

\begin{tabular}{|c|c|c|c|c|}
\hline 2.1 & ICU-beds dedicated to transplantation & $\begin{array}{l}\square \text { up to } 5 \\
\square>20\end{array}$ & $\square$ up to 10 & $\square$ up to 20 \\
\hline & IMC-beds dedicated to transplantation & $\begin{array}{l}\square \text { up to } 5 \\
\square>20\end{array}$ & $\square$ up to 10 & $\square$ up to 20 \\
\hline
\end{tabular}

2.3 Organs transplanted in your center $\square$ Liver transplantation - deceased

$\square$ Kidney transplantation - deceased

$\square$ Pancreas transplantation

$\square$ Heart transplantation - pediatric

$\square$ Lung transplantation - pediatric

2.4 Number of transplantations per year

2.5 Number of transplant surgeons
$\square$ up to 25
$\square>100$

$\square$ up to 5 $\square$ Liver transplantation - living

$\square$ Kidney transplantation - living

$\square$ Small bowel transplantation

$\square$ Lung transplantation - deceased

$\square$ Liver transplantation - pediatric

$\square$ Kidney transplantation - pediatric

$\square$ Heart transplantation

$\square$ Lung transplantation - living

\section{Effect of COVID-19 on your transplant program}
3.1 ... by shortage of resources
3.2 limiting factors
$\square$ Beds
$\square$ yes
$\square$ Equipment
$\square$ yes
3.3
3.4
$\square$ The whole transplant program is stopped
$\square$ Liver transplantation - pediatric is stopped
$\square$ Kidney transplantation - living is stopped
$\square$ Pancreas transplantation - is stopped
$\square$ Heart transplantation - pediatric is stopped
$\square$ Lung transplantation - living is stopped
program
$\square$ Liver transplantation - deceased is stopped
$\square$ Liver transplantation - only for high urgent or for the sickest patients
$\square$ Kidney transplantation - pediatric is stopped
$\square$ Small bowel transplantation - is stopped
$\square$ Heart transplantation - only for high urgent or for the sickest patients
$\square$ Lung transplantation - pediatric is stopped
$\square$ no
$\square$ Medication
$\square$ no
$\square$ Liver transplantation - living is stopped
$\square$ Kidney transplantation - deceased is stopped
$\square$ Kidney transplantation - only for high urgent or for the sickest patients
$\square$ Heart transplantation - is stopped
$\square$ Lung transplantation - deceased is stopped
$\square$ Lung transplantation - only for high urgent or for the sickest patients

$\square$ up to 50

$\square$ up to 100

$\square>20$

$\square$ up to 10

$\square$ up to 20

3.5 ... by hospital or governmental policy

Figure I Continue. 
EvaSys

Questionaire on COVID-19 and solid organ transplantation

3. Effect of COVID-19 on your transplant program [Fortsetzung]
3.6 restricted factors
$\square$ Beds
$\square$ Staff
3.7 related impairment of your transplant program
3.8
$\square$ The whole transplant program - is stopped
$\square$ Liver transplantation - pediatric is stopped
$\square$ Kidney transplantation - living is stopped
$\square$ Pancreas transplantation - is stopped
$\square$ Heart transplantation - pediatric is stopped
$\square$ Lung transplantation - living is stopped

$\square$ Equipment

$\square$ yes

$\square$ Liver transplantation - deceased is stopped

$\square$ Liver transplantation - only for high urgent or for the sickest patients

$\square$ Kidney transplantation pediatric is stopped

$\square$ Small bowel transplantation - is stopped

$\square$ Heart transplantation - only for high urgent or for the sickest patients

$\square$ Lung transplantation - pediatric is stopped

3.9 Do you personally agree with hospital or governmental policy

3.10 Protective measures against COVID-19 in your $\square$ yes $\quad \square$ no transplant program

3.11 ... modified standards in your transplant program

$\square$ Isolation of the recipient $\quad \square$ Visit ban

$\square$ yes $\quad \square$ no

$\square$ no

Medication

$\square$ Recipient wearing mask if together with health care professionals

Health care professionals wearing masks if together with recipient

$\square$ Changes in immunosuppressive regimen

$\square$ Changes in prophylactic medication with antibiotics

$\square$ Changes in prophylactic medication with antiviral therapy

3.12 Kind of isolation

Single room

3.13 Recipient wearing mask

3.15 COVID-19 PCR-testing of recipients

3.16 COVID-19 PCR-testing for donors

4. Support with relevant information

\section{Sufficient local information politics}

4.1 Hospital administration

4.2 Physicians chamber

4.3 Governmental

\section{Sufficient national information politics}

$\begin{array}{llll}4.4 & \text { Governmental } & \square \text { yes } & \square \text { no } \\ 4.5 & \text { Physicians chamber } & \square \text { yes } & \square \text { no } \\ 4.6 & \text { Societies } & \square \text { yes } & \square \text { no } \\ 4.7 & \text { OPOs (Organ procurement organization) } & \square \text { yes } & \square \text { no }\end{array}$

Sufficient international information politics (1)
Liver transplantation - living is stopped

$\square$ Kidney transplantation deceased is stopped

$\square$ Kidney transplantation - only for high urgent or for the sickest patients

$\square$ Heart transplantation - is stopped

Lung transplantation - deceased is stopped

$\square$ Lung transplantation - only for high urgent or for the sickest patients urgent or for the sickest pasjents 
4. Support with relevant information [Fortsetzung]
4.8 Governmental (EU)
4.9 Societies
$\square$ yes
$\square$ yes
$\square$ no
4.10 OPOs (Organ procurement organization)
$\square$ yes
$\square$ no

5. Personal opinion on how to deal with solid organ transplantation during COVID-19 pandemic
5.1 Continue transplant programs during
COVID-19 pandemic
$\square$ yes
no
$\square$ based on organ and/or urgency

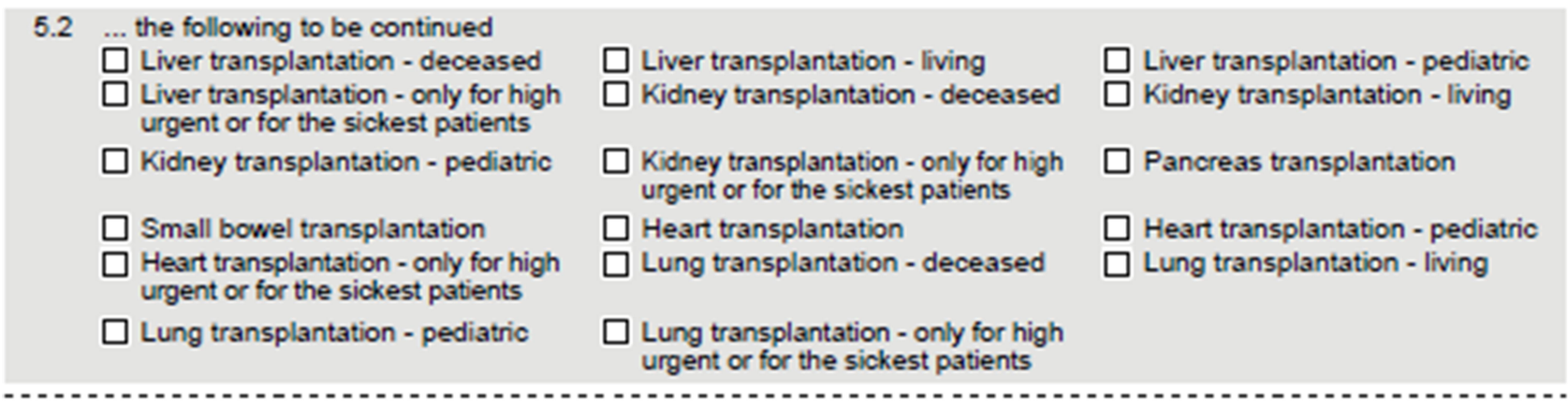

Thanks for your cooperation!

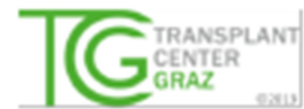

Figure I Questionnaire on COVID-19 and solid-organ transplantation.

(III) (Non)governmental information and policies (questions 4.1-4.10): These questions aimed to evaluate sufficiency of support with relevant information provided by local (hospital administration, physicians' chamber, governmental), national (governmental, physicians' chamber, societies, organprocurement organization), and international (governmental - European Union (EU), societies, organ-procurement organization) institutions.

(IV) Personal opinion on how to deal with SOT during COVID-19 (questions 3.9, 5.1, 5.2): The main question was if transplant centers should continue their programs in general or based only on organ and/or urgency. If the latter of possibilities was answered with a "yes", the specific programs to be continued had to be selected.

\section{Data Management and Statistical Analysis}

The questionnaire was collected anonymously and data collected imported automatically and evaluated using the EvaSys program. ${ }^{21}$ Data were displayed as descriptive statistics.

\section{Results General Data}

The response rate was $37.4 \%$ (58 of 155) of centers from 17 European countries (Figure 2). Among these, 8\% had a total of $>2,000,24.1 \%$ up to $2,000,25.9 \%$ up to 1,500 , $25.9 \%$ up to 1,000 , and $15.5 \%$ up to 500 beds. Concerning total ICU/IMC beds, $17.2 \% / 8.6 \%$ transplant centers had $>150$ beds, $19 \% / 8.6 \%$ up to 150 beds, $27.6 \% / 29.3 \%$ up to 100 beds, $25.9 \% / 34.5 \%$ up to 50 beds, and $10.3 \% / 19 \%$ up to 20 beds, respectively.

\section{General Information on Transplant \\ Centers}

All kinds of SOT were represented in the survey (Figure 3). Total transplantations $>100$ per year irrespective of type of organ were given in $53.4 \%$ of centers, up to 100 in $25.9 \%$, up to 50 in $17.2 \%$, and up to 25 in $3.4 \%$. There were $>20$ transplant surgeons in $5.2 \%$, up to 20 in $27.6 \%$, up to ten in $34.5 \%$ and up to five in $32.8 \%$ of the surveyed transplant centers. The number of ICU/IMC beds dedicated to 


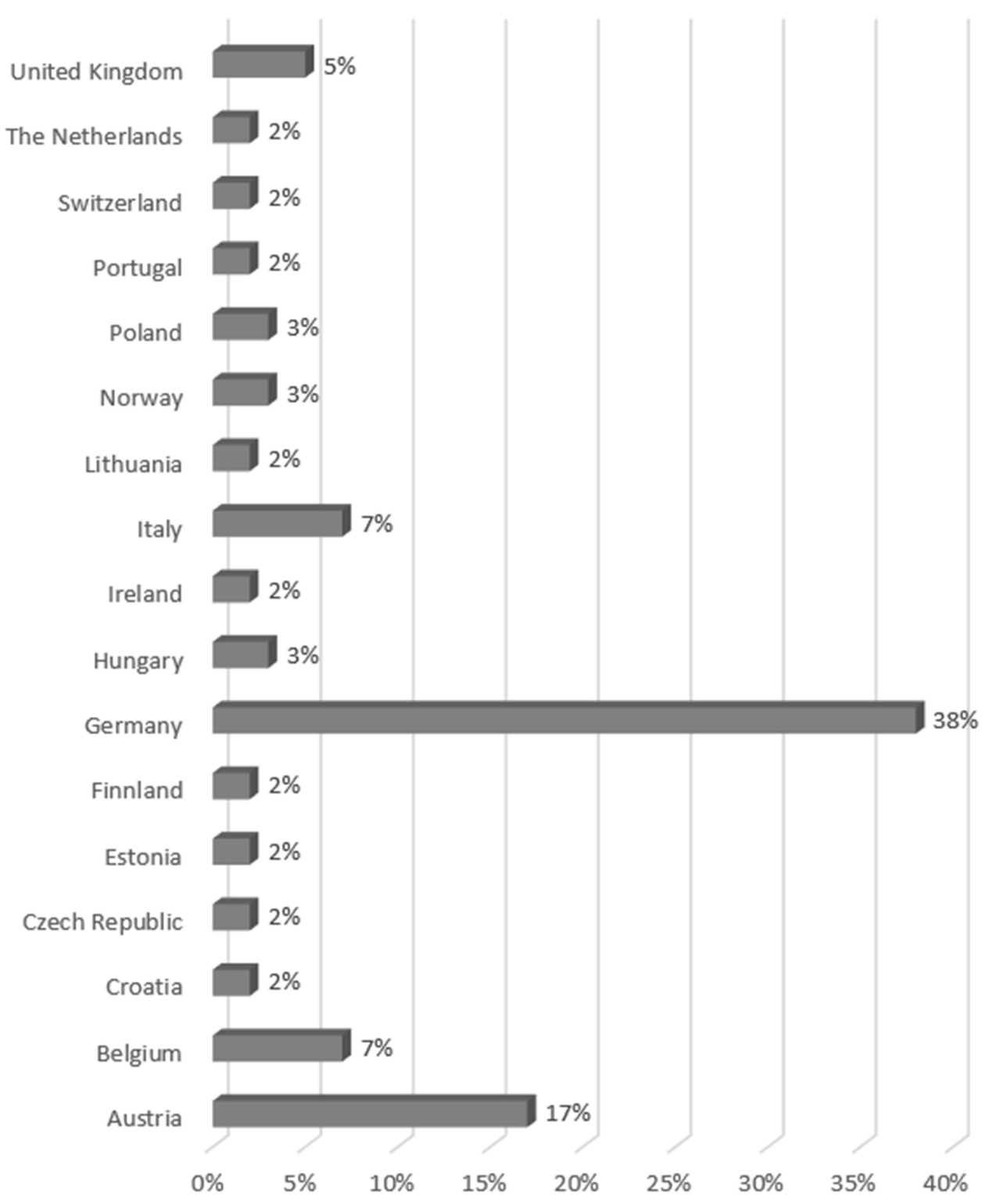

Figure 2 Country ( $n=17)$ distribution of completed surveys.

transplantation comprised $>20$ in $5.2 \% / 5.2 \%$ of transplant centers, up to 20 in $6.9 \% / 17.2 \%$, up to ten beds in $34.5 \%$ / $25.9 \%$, and up to five in $53.4 \% / 51.7 \%$, respectively.

\section{Effect of COVID-I9 on SOT}

Overall, 84.5\% reported an effect of COVID-19 on SOT. In $49 \%$ of these $(n=24)$ a current shortage of resources as an effect of the COVID-19 was stated. Limitation factors were beds (83.3\%), equipment (25\%), and staff (37.5\%). Medication was not a restricting factor. In these centers, related impairment of transplant programs was declared in $95.8 \%$. There had been complete suspension of the entire transplant center in $8.7 \%$, of deceased kidney transplantation in $39.1 \%$, of living kidney transplantation in $65.2 \%$, of pediatric kidney transplantation in $17.4 \%$, of pancreas transplantation in $43.5 \%$, and of small-bowel transplantation in $17.4 \%$ (Figure 4). Only the deceased liver-transplant program was not stopped in any center.

Hospital or governmental policies caused an effect of $51 \%$ on transplant centers, with related impairment of the programs in $96 \%$. Limitation factors were beds (92\%), equipment $(20 \%)$, and staff $(28 \%)$, but not medication. Due to the policies, $8.3 \%$ of entire transplant programs had been stopped, $50 \%$ of deceased kidney transplantation, $66.7 \%$ of living kidney transplantation, and $45.8 \%$ of pancreas transplantation (Figure 5). 




Figure 3 Organs transplanted in centers of respondents.

Due to differeing severity of COVID-19 pandemic, health-care systems, and governments among European countries there was a certain heterogenity between countries concerning the impact on their transplant centers (Table 1).

Respondents from Italy reported an effect of COVID-19 on transplant programs of $100 \%$ (50\% shortage of resources and $50 \%$ hospital or governmental policies). In up to $25 \%$, the entire transplant program had been stopped. In Austria, $60 \%$ of resources were limited by hospital and/or governmental policies, in Germany, this was only $22.7 \%$. In Austria, the deceased kidney transplantation program had stopped in $100 \%$, the living kidney program in $83.3 \%$, the pediatric kidney program in $50 \%$, and the pancreas program in $83.3 \%$. In Germany, the deceased kidney transplantation program was continued, but the living kidney program was stopped in 80 , and the pancreas transplantation program in 50\%.

A total of $13.8 \%$ of transplant centers disagreed with current policies. However, in some European countries there agreement of only $50-60 \%$ with hospital or governmental policies concerning COVID-19 (Table 1).

\section{Protective Measures Against COVID-19 in Transplant Centers}

Most of the transplant centers (93.1\%) implemented protective measures against COVID-19. Recipients were isolated in $64.8 \%$ of centers (single room in $71.4 \%$, single room + airlock in $17.1 \%$, single room + airlock + overpressure system in $11.4 \%$ ). Visit bans were in place in $77.8 \%$, and number of health care professionals at once with recipient had been restricted to two in $40.7 \%$ of centers. Further modified standards comprised wearing of masks for both recipient and health-care professionals (surgical mask 85\%/ $83.3 \%$, FFP2 mask 12.5\%/14.6\%, FFP3 mask 2.5\%/ $2.1 \%$ of centers). Changes in immunosuppressive regimen were carried out in only $7.4 \%$, and no changes in prophylactic medication with antibiotic, antimycotic, or antiviral therapy were reported. COVID-19 PCR testing of recipients was found in $93.1 \%$ and of donors in $94.8 \%$. 
Lung transplantation - only high urgent or for the sickest

Lung transplantation - pediatric is stopped

Lung transplantation - living is stopped

Lung transplantation - deceased is stopped

Heart transplantation - only high urgent or for the sickest

Heart transplantation -pediatric is stopped

Heart transplantation - is stopped

Small bowel transplantation - is stopped

Pancreas transplantation - is stopped

Kidney transplantation - only high urgent or for the sickest

Kidney transplantation - pediatric is stopped

Kidney transplantation - living is stopped

Kidney transplantation - deceased is stopped

Liver transplantation - only high urgent or for the sickest

Liver transplantation - pediatric is stopped

Liver transplantation - living is stopped

Liver transplantation - deceased is stopped

The whole transplant program is stopped

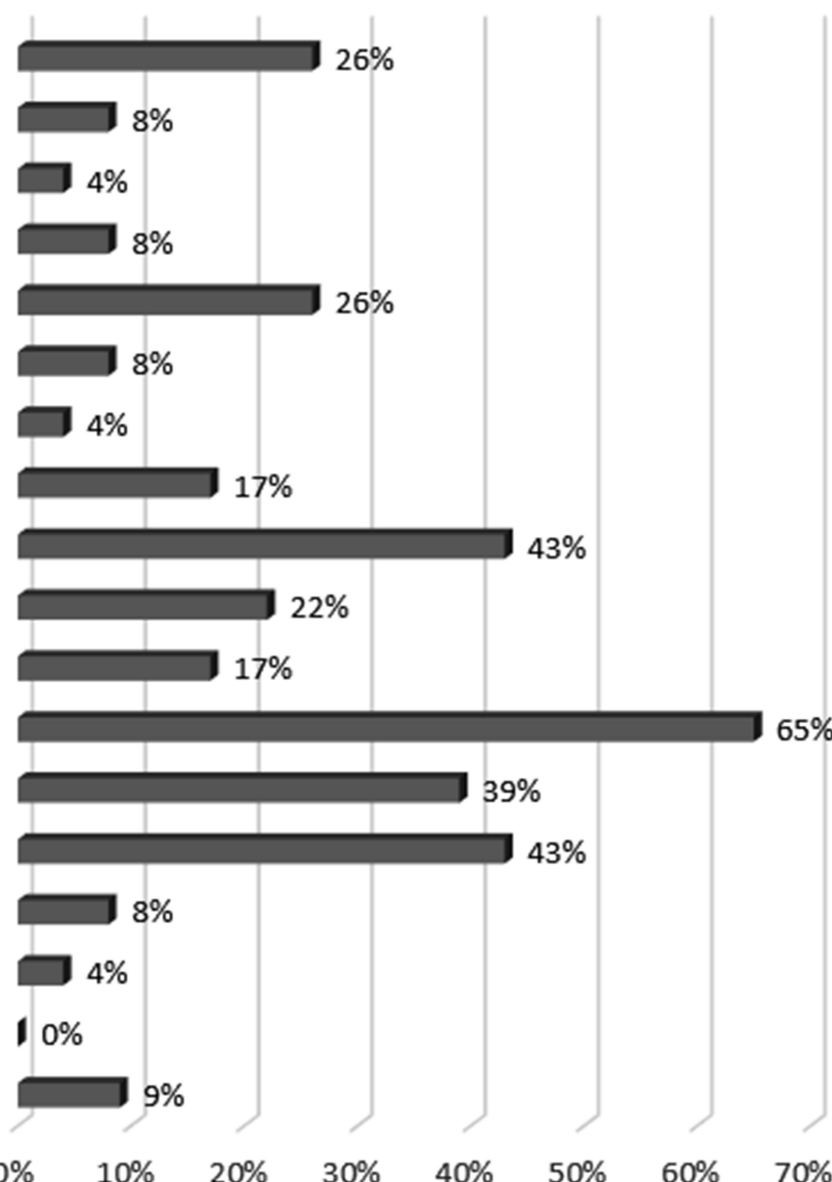

Figure 4 Shortage of resources as effect on transplant programs $(n=23)$.

\section{Feedback on Support with Relevant Information}

Respondents felt adequately informed about the topic by local (hospital administration 91.4\%, physicians' chamber $77.6 \%$, governmental $77.6 \%$ of centers), national (governmental 79.3\%, physicians' chamber 75.9\%, societies $86.2 \%$, organ-procurement organizations $75.9 \%$ of centers), and international (governmental — EU 56.9\%, societies $79.3 \%$, organ-procurement organizations $60.3 \%$ of centers) information policies.

\section{Personal Opinions on How to Deal with SOT During COVID-19}

Of all transplant centers, $96.6 \%$ would continue transplant activity in general (52\%) during COVID-19 or based on organ and/or urgency (48\%).

\section{Discussion}

Survey results demonstrated a tremendous impact of COVID-19 on transplant centers in Europe. Related

impairment of transplant activity was caused either by actual shortage of resources or strategic preparedness, given by hospital/governmental policies. Both reasons for restrictions were present to the same extent. Actual impairment by number, however, remains unclear.

This is the first assessment of the impact of COVID-19 on SOT in Europe. Other surveys that have been carried out recently ${ }^{22-28}$ focused on different topics and were carried out onlywithin one or a few countries. A survey with similar question was carried out in the US. ${ }^{29}$ This survey may be the basis for speculating on the shortage of ICU capacity needed to provide health-care support for both COVID-19 and all other patients in most countries.

\section{Impact of Shortage of Resources on Transplant Centers}

At the height of the pandemic, several European countries were affected by total utilization of the capacity of their health systems (eg, Italy, Spain, and France) ${ }^{5,7}$ Both restrictions and even suspension of transplant programs were not 


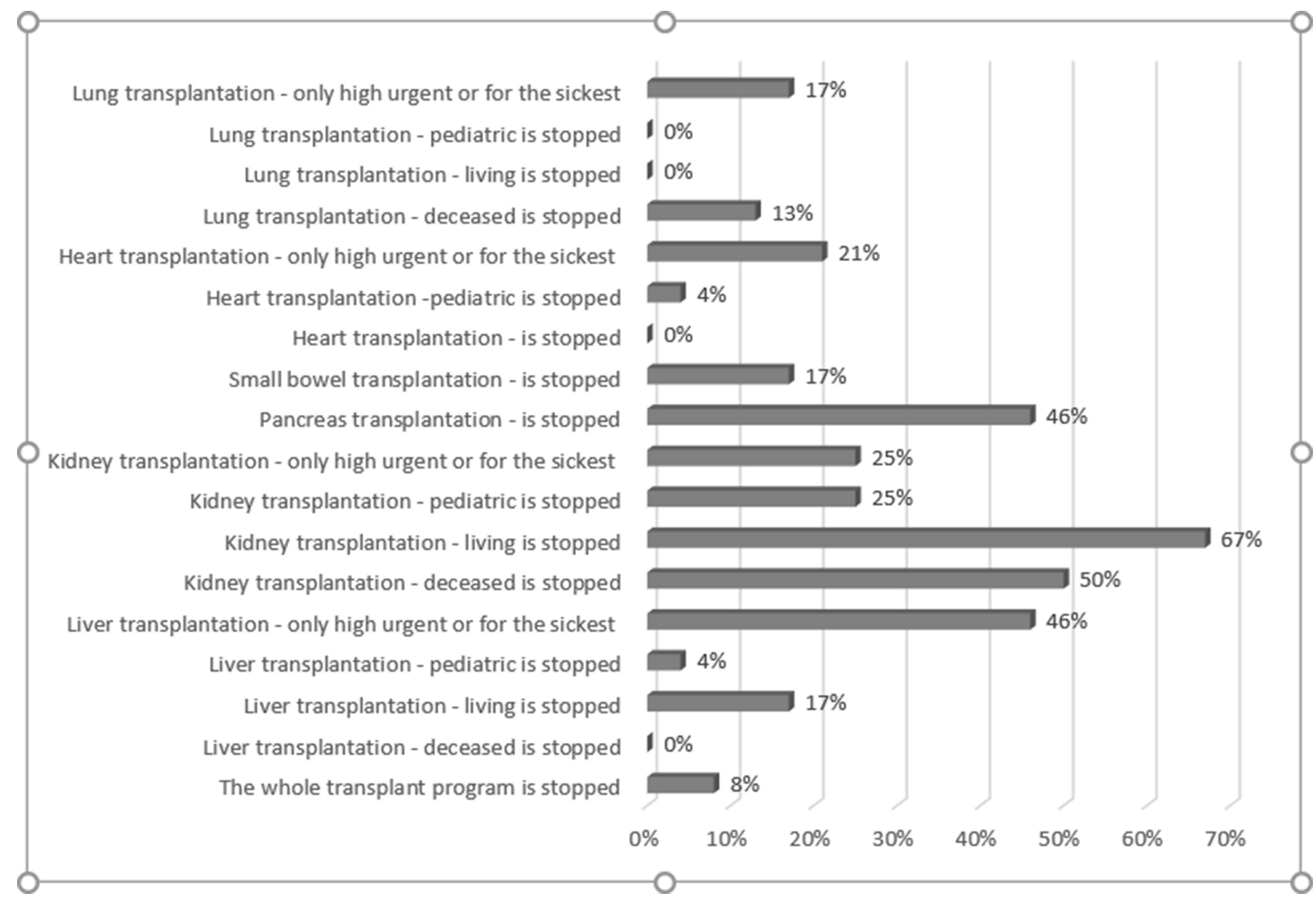

Figure 5 Hospital or governmental policy as effect on transplant programs $(n=24)$.

reflected by the necessity based on the ICU capacity provided (Table 2) in various corresponding countries (eg, Germany). The characteristics of the health-care systems and the sociodemographic needs of the different European countries vary widely, and the measures recommended by the WHO have been applied differently across different countries and regions. During the pandemic, such countries as Germany, which have more ICU beds per head of population (Table 2), were able to help other European nations that were temporarily or continuously overwhelmed with an excess of cases (eg, Italy). In Italy, ICUs had to be expanded and new hospitals built to cope with the demands of the escalating number of COVID-19 patients. Furthermore, human resources were reorganized and retired professionals and

Table I Impact of COVID-19 pandemic on transplant centers and personal opinions of countries with two or more respondents

\begin{tabular}{|l|c|c|c|c|}
\hline $\begin{array}{l}\text { Country } \\
\text { Respondents n 2 }\end{array}$ & $\begin{array}{l}\text { Impairment of } \\
\text { transplant programs } \\
\text { by shortage of } \\
\text { resources }\end{array}$ & $\begin{array}{l}\text { Impairment of transplant } \\
\text { programs by hospital or } \\
\text { governmental policy }\end{array}$ & $\begin{array}{l}\text { Agreement } \\
\text { with policy }\end{array}$ & $\begin{array}{l}\text { Personal Opinion: continue } \\
\text { transplant program (in general, } \\
\text { based on organ and/or urgency) }\end{array}$ \\
\hline Austria & $60 \%$ & $70 \%$ & $60 \%$ & $100 \%(30 \%, 70 \%)$ \\
Belgium & $75 \%$ & $100 \%$ & $50 \%$ & $100 \%(50 \%, 50 \%)$ \\
Germany & $22.7 \%$ & $13.6 \%$ & $95.5 \%$ & $95.5 \%(66.6 \%, 33.3 \%)$ \\
Hungary & $50 \%$ & $100 \%$ & $700 \%$ & $100 \%(0 / 100 \%)$ \\
Italy & $50 \%$ & $50 \%$ & $100 \%$ & $100 \%(50 \%, 50 \%)$ \\
Norway & 0 & 0 & $100 \%$ & $100 \%(100 \% / 0)$ \\
Poland & $100 \%$ & $50 \%$ & $100 \%$ & $100 \%(0 / 100 \%)$ \\
UK & $66.6 \%$ & $66.6 \%$ & $66.6 \%(50 \%, 50 \%)$ \\
\hline
\end{tabular}


Table 2 Case loads (cumulative total in January 202I, WHO COVID-19 Dashboard), COVID deaths/million inhabitants, and ICU beds/100,000 inhabitants of surveyed countries

\begin{tabular}{|l|c|c|c|}
\hline Country & Cases - cumulative total & COVID deaths/million inhabitants & ICU beds/ I00,000 inhabitants \\
\hline UK & $3,647,467$ & 1,370 & 6.6 \\
Italy & $2,466,813$ & 1,429 & 12.5 \\
Germany & $2,141,655$ & 639 & 29.2 \\
Poland & $1,478,119$ & 942 & 6.9 \\
Netherlands & 948,933 & 803 & 6.4 \\
Czech Republic & 940,004 & 1,458 & 11.6 \\
Belgium & 693,666 & 1,801 & 15.9 \\
Portugal & 636,190 & 1,079 & 4.2 \\
Switzerland & 506,775 & 1,063 & 11.0 \\
Austria & 401,534 & 834 & 21.8 \\
Hungary & 360,418 & 1,214 & 13.8 \\
Croatia & 229,054 & 1,189 & 4.3 \\
Ireland & 187,554 & 620 & 6.5 \\
Lithuania & 177,166 & 987 & 15.5 \\
Norway & 60,803 & 101 & 8.0 \\
Finland & 41,915 & 118 & 6.1 \\
Estonia & 40,975 & 295 & 14.6 \\
\hline
\end{tabular}

volunteers sent to hospitals in critical areas. In this situation, other patients, such as cancer or transplant patients, could no longer be cared for, due to lack of resources, above all limited beds, staff, and equipment. As for our survey, transplant centers in Italy were affected $100 \%$ (50\% by shortage of resources and $50 \%$ by hospital or governmental policies). In up to $25 \%$, whole transplant centers were closed. However, $25 \%$ of the responding centers did not agree with health-care policy. All the queried centers would have liked to continue their transplant activity during COVID-19 (52\% in general, $48 \%$ based on organ and/or urgency) in order to be able to continue caring for their patients. US data comparable to those from Italy were published recently. ${ }^{29}$ Results of a nationwide survey demonstrated complete suspension rates of living kidney transplantation in up to $71.8 \%$ and living liver transplantation in up to $67.7 \%$. Restrictions of deceased kidney-transplantation programs were declared in $84 \%$ and of deceased liver-transplant programs in $73.3 \%$. Almost no restrictions were placed on heart- or lungtransplantation programs.

A completely different situation was observed in other European countries, where the severity of the COVID-19 pandemic was not that substantial. In order to be prepared for a possibly extreme COVID-19 situation, resources were kept free for safety reasons and thus restricted. Strategically prepared countries were Austria and Germany, for example, but interestingly there were differences between them. While in Austria, 60\% of resources were limited by hospital and/or governmental policy, in Germany it was only $22.7 \%$. In Austria, the deceased kidney-transplantation program was 100\% stopped, while in Germany it was continued. While transplant centers in Germany mostly agreed with hospital or governmental policies, in Austria there was disagreement of $40 \%$. Almost all transplant centers in both countries (Austria 100\%, Germany 95.5\%) agreed to continue transplantation during COVID-19 in general (Austria 30\%, Germany $66.6 \%$ ) or based on organ and/or urgency (Austria 70\%, Germany 33.3\%).

Our results showed that the resources of all transplant centers in Europe were more or less affected by COVID19. The extent of the negative effect on transplantation depended on the severity of the infection wave, but also on strategic measures within individual countries. An important goal for the future must be to learn from the experiences of all countries and develop strategies for the future that can support a reduction in the collateral damage of pandemics on transplant centers. ${ }^{30-32}$ It must be clear that a dramatic increase in patients requires an increase in resources, unless restrictions treating patients with ICU/ IMC requirements in need of isolation are accepted.

Another approach to continuing SOT is restriction of treatment to highly selected patients. As an example, the sickest-first strategy could be applied. As an alternative, 
the healthiest patients are treated on the assumption of better resistance against COVID-19 infection and thus better survival after transplantation. Data from this survey clearly showed that up to $33.3 \%$ of the centers transplanted only highly urgent or the sickest patients. Deceased and pediatric programs should be continued over living transplant programs. However, transplanting only healthier recipients with the best-quality organs and lowest risk of delayed graft function might also be a good strategy. ${ }^{29}$ When trying to select, some criteria might be considered: kidney transplantation, preemptive transplantation, highly sensitized patients, those with negative cross matching, or higher-acuity patients. In cases of liver transplantation, patients could be stratified on the severity of their illness, first transplants, and those with tumors without other options. For heart and lung transplantation as lifesaving procedures, there were almost no restrictions and there should not be any in future. In any case, COVID-19 recipient- and donor- testing availability is mandatory, and attention should be paid to a low-risk COVID-19 setting (both donor and recipient SARS-CoV2-negative).

\section{Unknown Effects of COVID-I9 on SOT}

In the middle of March 2020, when the COVID-19 pandemic started, knowledge on the impact of the virus in a transplant setting including immunosuppression was scarce and discouraging. ${ }^{19,33,34}$ Therefore, some transplant centers considered stopping their programs ${ }^{11,12,20}$ or restricting transplantation to highly urgent or riskstratified patients. Risk stratification was especially difficult, due to pending data or even scores. During the following weeks, many recommendations from transplantation or surgical societies, clinical studies, and case reports were published, ${ }^{35-39}$ enabling transplant centers to get a first overview on the actual risk of the virus for transplant recipients. First experiences of transplant-programs center in Europe demonstrated data with quite good survival of transplanted patients during the outbreak, and no specific reasons to stop transplant programs were found. ${ }^{40}$ Of course, a careful risk-benefit analysis for performing transplantation should be considered, and in particular the risk fof COVID-19 infection in transplant recipients has to be minimized. The results of our survey demonstrated that COVID-19 PCR testing of recipients was performed in $93.1 \%$ and of donors in $94.8 \%$. Furthermore, most of the transplant centers (93.1\%) implemented protective measures against COVID-19 in their transplant programs.
In our center, liver transplantation was safely performed during COVID-19 in a low-risk setting (both donor and recipient SARS-CoV2--negative, low disease-severity recipients [labMELD score <25], and a low donor risk-index graft). ${ }^{41}$ However, data concerning the impact of COVID-19 on patients after transplantation are still rare and controversial; therefore, we urgently need data from further studies that could provide important information for the care of transplant recipients.

\section{Conclusion}

This is the first survey to give an overview of 58 transplant centers within 17 European countries and their framework for SOT during the COVID-19 pandemic. Results of this survey suggest a desperate need for ICU capacity during COVID-19 in most countries to guarantee adequate and timely treatment of other patient cohorts.

\section{Acknowledgment}

We especially thank all responding transplant centers for their kind participation.

\section{Author Contributions}

All authors made substantial contributions to conception and design, acquisition of data, or analysis and interpretation of data, took part in drafting the article or revising it critically for important intellectual content, agreed to submit to the current journal, gave final approval to the version to be published, and agree to be accountable for all aspects of the work.

\section{Disclosure}

The authors of this manuscript have no conflicts of interest to disclose.

\section{References}

1. Huang C, Wang Y, Li X, et al. Clinical features of patients infected with 2019 novel coronavirus in Wuhan, China. Lancet. 2020;395(10223):497-506. doi:10.1016/S0140-6736(20)30183-5

2. Li Q, Guan X, Wu P, et al. Transmission dynamics in Wuhan, China, of novel coronavirus-infected pneumonia. N Engl J Med. 2020;382 (13):1199. doi:10.1056/NEJMoa2001316

3. Statement on the second meeting of the International Health Regulations (2005) Emergency Committee regarding the outbreak of novel coronavirus (2019-nCoV). World Health Organization (WHO); January 30,2020

4. WHO Director-General's opening remarks at the media briefing on COVID-19-11 March 2020. World Health Organization (WHO); March 11, 2020. 
5. Roser M, Ritchie H, Ortiz-Ospina E Coronavirus disease (COVID19) - research and statistics. Wayback Machine; March 13, 2020. Available from: ourworldindata.org/coronavirus. Accessed March 14, 2020.

6. Henley $\mathrm{J}$ More than $250 \mathrm{~m}$ in lockdown in EU as Belgium and Germany adopt measures. The Guardian. ISSN 0261-3077. Archived from the original on 1 April 2020. Accessed April 4, 2020.

7. WHO Coronavirus (COVID-19) Dashboard. Available from: https:// covid19.who.int. February 1, 2021. Accessed May 28, 2021.

8. American College of Surgeons. Available from: https://www.facs.org/ covid-19/clinical-guidance/triage. March 16, 2020. Accessed May 28, $2021 \mathrm{https}: / /$ www.facs.org/covid-19/clinical-guidance/triage.

9. Gandolfini I, Delsante M, Fiaccadori E, et al. COVID-19 in kidney transplant recipients. Am J Transplant. 2020;20(7):1941-1943. doi:10.1111/ajt.15891

10. Zhu L, Xu X, Ma KE, et al. Successful recovery of COVID-19 pneumonia in a renal transplant recipient with long-term immunosuppression. Am J Transplant. 2020;20(7):1859-1863. doi:10.1111/ajt.15869

11. Michaels MG, La Hoz RM, Danziger-Isakov L, et al. Coronavirus disease 2019: implications of emerging infections for transplantation. Am J Transplant. 2020;20(7):1768-1772. doi:10.1111/ajt.15832

12. Ali T, Al-Ali A, Fajji L, et al. Coronavirus disease-19: disease severity and outcomes of solid organ transplant recipients: different spectrums of disease in different populations? Transplantation. 2021;105(1):121-127. doi:10.1097/TP.0000000000003433

13. Akalin E, Azzi Y, Bartash R, et al. Covid-19 and kidney transplantation. N Engl J Med. 2020;382:2475-2477. doi:10.1056/ NEJMc2011117

14. Nair V, Jandovitz N, Hirsch JS, et al. COVID-19 in kidney transplant recipients. Am J Transplant. 2020;20:1819-1825. doi:10.1111/ ajt. 15967

15. Columbia University Kidney Transplant Program. Early description of coronavirus 2019 disease in kidney transplant recipients in New York. J Am Soc Nephrol. 2020;31:1150-1156. doi:10.1681/ ASN.2020030375

16. Nacif LS, Zanini LY, Waisberg DR, et al. COVID-19 in solid organ transplantation patients: a systematic review. Clinics (Sao Paulo). 2020;75:e1983. doi:10.6061/clinics/2020/e1983

17. Pereira MR, Mohan S, Cohen DJ, et al. COVID-19 in solid organ transplant recipients: initial report from the US epicenter. $\mathrm{Am}$ $J$ Transplant. 2020;20:1800-1808. doi:10.1111/ajt.15941

18. Hoek RAS, Manintveld OC, Betjes MGH, et al. COVID-19 in solid organ transplant recipients: a single-center experience. Transpl Int. 2020;33:1099-1105. doi:10.1111/tri.13662

19. Kumar D, Manuel O, Natori Y, et al. COVID-19: a global transplant perspective on successfully navigating a pandemic. Am J Transplant. 2020;20(7):1773-1779. doi:10.1111/ajt.15876

20. Gori A, Dondossola D, Antonelli B, et al. Coronavirus disease 2019 and transplantation: a view from the inside. Am J Transplant. 2020;20 (7):1939-1940. doi:10.1111/ajt.15853

21. evasys. Available from: https://evasys.de/en/healthcare/. Accessed May 28/2021.

22. Doná D, Canizales JT, Benetti E, et al. Pediatric transplantation in Europe during the COVID-19 pandemic: early impact on activity and healthcare. Clin Transplant. 2020;34(10):e14063. doi:10.1111/ ctr. 14063

23. Vistoli F, Furian L, Maggiore U, et al. COVID-19 and kidney transplantation: an Italian survey and consensus. $J$ Nephrol. 2020;33:667-680. doi:10.1007/s40620-020-00755-8
24. Lentine K, Vest L, Schnitzler M, et al. Survey of US living kidney donation and transplantation practices in the COVID-19 era. Kidney Int Rep. 2020;5(11):1894-1905. doi:10.1016/j.ekir.2020.08.017

25. Rivinius R, Kaya Z, Schramm R, et al. COVID-19 among heart transplant recipients in Germany: a multicenter survey. Clin Res Cardiol. 2020;109:1531-1539. doi:10.1007/s00392-020-01722-w

26. Coiffard B, Lepper PM, Prud'Homme E, et al. Management of lung transplantation in the COVID-19 era - An international survey. $\mathrm{Am}$ $J$ Transplant. 2020. doi:10.1111/ajt.16368.

27. Michel S, Witt C, Gottlieb J, et al. Impact of COVID-19 on lung transplant activity in germany-a cross-sectional survey. Thorac Cardiovasc Surg. 2020. doi:10.1055/s-0040-1715436

28. Jothimani D, Daniel H, Danielraj S, et al. COVID-19 lockdown: impact on liver transplant recipients- a single centre survey. $J$ Assoc Physicians India. 2020;68(8):96.

29. Boyarsky BJ, Po-Yu Chiang T, Werbel WA, et al. Early impact of COVID-19 on transplant center practices and policies in the United States. Am J Transplant. 2020;20(7):1809-1818.

30. Chopra V, Toner E, Waldhorn R, et al. How should U.S. hospitals prepare for coronavirus disease 2019 (COVID-19)? Ann Intern Med. 2020;172(9):621-622. doi:10.7326/M20-0907

31. Hu XH, Niu WB, Zhang JF, et al. [Thinking of treatment strategies for colorectal cancer patients in tumor hospitals under the background of coronavirus pneumonia.]. Zhonghua Wei Chang Wai Ke Za Zhi. 2020;23(3):201-208. (Chinese). doi:10.3760/cma.j. cn.441530-20200217-00058

32. Zhu W, Wang Y, Xiao K, et al. Establishing and managing a temporary coronavirus disease 2019 specialty hospital inWuhan, China. Anesthesiology. 2020;132(6):1339-1345. doi:10.1097/ ALN.0000000000003299

33. Huang JF, Zheng KI, George J, et al. Fatal outcome in a liver transplant recipient with COVID-19. Am J Transplant. 2020;20 (7):1907-1910. doi:10.1111/ajt.15909

34. AlGhamdi M, Mushtaq F, Awn N, et al. MERS CoV infection in two renal transplant recipients: case report. Am J Transplant. 2015;15 (4):1101-1104. doi:10.1111/ajt.13085

35. Fix OK, Hameed B, Fontana RJ, et al. Clinical best practice advice for hepatology and liver transplant providers during the COVID-19 pandemic: AASLD expert panel consensus statement. Hepatology. 2020;72(1):287-304. doi:10.1002/hep.31281

36. Bhoori S, Rossi RE, Citterio D, et al. COVID-19 in long-term liver transplant patients: preliminary experience from an Italian transplant centre in Lombardy. Lancet Gastroenterol Hepatol. 2020;5 (6):532-533. doi:10.1016/S2468-1253(20)30116-3

37. Müller H, Kniepeiss D, Stauber R, et al. Recovery from COVID-19 following hepatitis $\mathrm{C}$, human immunodeficiency virus infection and liver transplantation. Am J Transplant. 2020;20(11):3255-3256. doi:10.1111/ajt.16107.

38. Martino F, Plebani M, Ronco C. Kidney transplant programmes during the COVID-19 pandemic. Lancet Respir Med. 2020;8(5): e39. doi:10.1016/S2213-2600(20)30182-X

39. Pan L, Zeng J, Yang H. Challenges and countermeasures for organ donation during the SARS-CoV-2 epidemic: the experience of Sichuan Provincial People's Hospital. Intensive Care Med. 2020;46 (5):844-845. doi:10.1007/s00134-020-05978-8

40. Maggi U, De Carlis L, Yiu D, et al. The impact of the COVID-19 outbreak on liver transplantation programs in Northern Italy. $\mathrm{Am}$ $J$ Transplant. 2020;20(7):1840-1848. doi:10.1111/ajt.15948

41. Feng S, Goodrich NP, Bragg-Gresham JL, et al. Characteristics associated with liver graft failure: the concept of a donor risk index. Am $J$ Transplant. 2006;6:783-790. doi:10.1111/j.16006143.2006.01242.x 


\section{Publish your work in this journal}

Risk Management and Healthcare Policy is an international, peerreviewed, open access journal focusing on all aspects of public health, policy, and preventative measures to promote good health and improve morbidity and mortality in the population. The journal welcomes submitted papers covering original research, basic science, clinical \& epidemiological studies, reviews and evaluations, guidelines, expert opinion and commentary, case reports and extended reports. The manuscript management system is completely online and includes a very quick and fair peer-review system, which is all easy to use. Visit http://www.dovepress.com/testimonials.php to read real quotes from published authors.

Submit your manuscript here: https://www.dovepress.com/risk-management-and-healthcare-policy-journal 